\title{
Electron Microscopic Study of the Zoospores of Lagenisma coscinodisci
}

\author{
D. K. Chakravarty \\ Institut für Meeresforschung, Bremerhaven, West Germany
}

Received July 20, 1976

The fungus Lagenisma coscinodisci Drebes is an endobiotic parasite of the centric marine diatom Coscinodiscus granii (Chakravarty 1970). The fungus belongs to the family Lagenidiaceae of the order Lageniciales (Drebes 1966). Only the asexual phase of the life cycle of the fungus is known. The fungus produces filamentous holocarpic thallus inside the diatom cell. On maturity the whole thallus is transformed into sporangium. The zoospores released by the mature sporangia settle on the silica wall of the diatoms and a new series of infection starts. Considering the nature of the hard siliceous wall of the diatoms, it is rather fascinating to study how it is possible for the delicate zoospores to penetrate the cell wall and to initiate new infection. The present electron microscopic study of the zoospores was undertaken with a view to find out if the zoospores have any special structures which help in this rather difficult penetration process.

\section{Material and methods}

A pure culture of Coscinodiscus granii infected with $L$. coscinodisci prepared according to the method described earlier (Chakravarty 1970) was used in this investigation.

Electron microscopic preparation of the zoospores for revealing the surface structures of the flagella

The method used is that of Gaertner (1964) with some modifications. The zoospores while releasing from the sporangium, were collected by a very thin glass pipette. The zoospore suspension was then transferred to a platinum loop was exposed to osmic acid vapour for about 10 seconds. The zoospores suspension, thus fixed was made salt free in the following way. The supporting membrane of Formver (Serve Heidelberg) was placed on $10 \mathrm{~mm}$ thick plates of $4 \%$ Difco Agar, and the fixed suspension in the loop was transferred on the membrane. The salts in the zoospore suspension diffuse in the agar and after about 48 hours, the zoospores were, in some cases completely free from salts.

The agar layer with membrane supporting the zoospores was then cut into about 4 square $\mathrm{mm}$ pieces and each one of them was floated singly on the surface of water and was transferred to a copper grid from below. The grids were then

1 Present address: Department of Plant Pathology, Faculty of Agriculture, Bidhan Chandra Krishi Viswavidyalaya, P. O. Kalyani, Nadia, West Bengal, India. 
dried in a dessicator. The shadow casting was done with chromium. The preparations were examined under a Siemens electron microscope (Electron Microscope I) in the Statt Institut für Allgemeine Botanik of the University of Hamburg.

\section{Electron microscopic preparation for the fine structures of zoospores}

A small drop of zoospore suspension was taken in a platinum loop and fixed with osmic acid vapour for 10 seconds. The drop was then placed on a plate of $2 \%$ agar coloured with Indian Ink. On the zoospore suspension was later placed a drop of $2 \%$ agar without any coloring agent. The agar block was passed through a series of different salt concentrations ending in distilled water and stained with $1 \%$ uranyl acetate. Afterwards the blocks were dessicated in acetone series and finally embedded in Vestopal W. The polymerization was done at first at $60^{\circ} \mathrm{C}$ for 12 hours followed by $70^{\circ} \mathrm{C}$ for 24 hours. Sections were made in ultramicrotome (Reichert) with glass knife and counterstained in aqueous uranyl acetate, followed by lead citrate. As the agar layer supporting the zoospores were stained, it was comparatively less difficult to trace the zoospores in the Vestopal block while sectioning.

\section{Results}

Surface structure of the flagella

The zoospores of the fungus (Fig. 1) have two equal flagella, one of which is of whiplash type (WH) and the other is of tinsel (T). The whiplash flagellum is

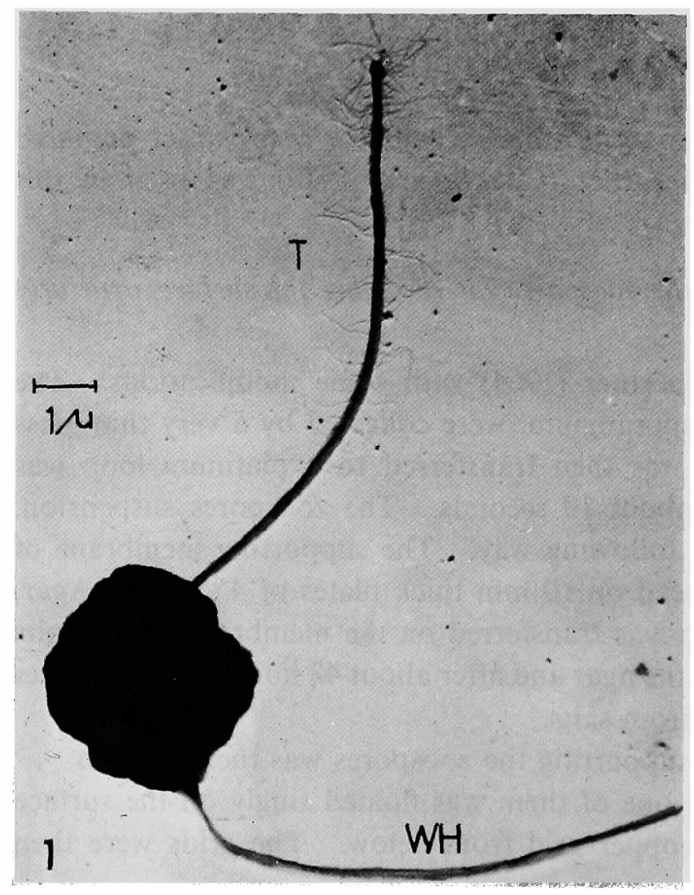

Fig. 1. Surface structure of the zoospore showing one tinsel (T) and other whiplash (WH) flagella. $\times 8300$. about 15 to $18 \mathrm{~m} \mu$ in diameter. The end piece generally found in whiplash flagellum is absent in the zoospore examined. The average diameter of the tinsel flagellum is about $12 \mathrm{~m} \mu$. The lateral hairs seem to be more concentrated at the tips and measure $1.2 \mathrm{~m} \mu$ in diameter and 6 to $12 \mathrm{~m} \mu$ in length. Each of the lateral hairs end in very fine tips measuring about 4 to $8 \mathrm{~m} \mu$ long. A close observation of the electron dense and electron light areas on the flagellar body shows that these form a definite pattern and indicates that the flagellar body is not completely cylindrical in shape.

Fine structures of the zoospore The mitochondria ( $M$ in 


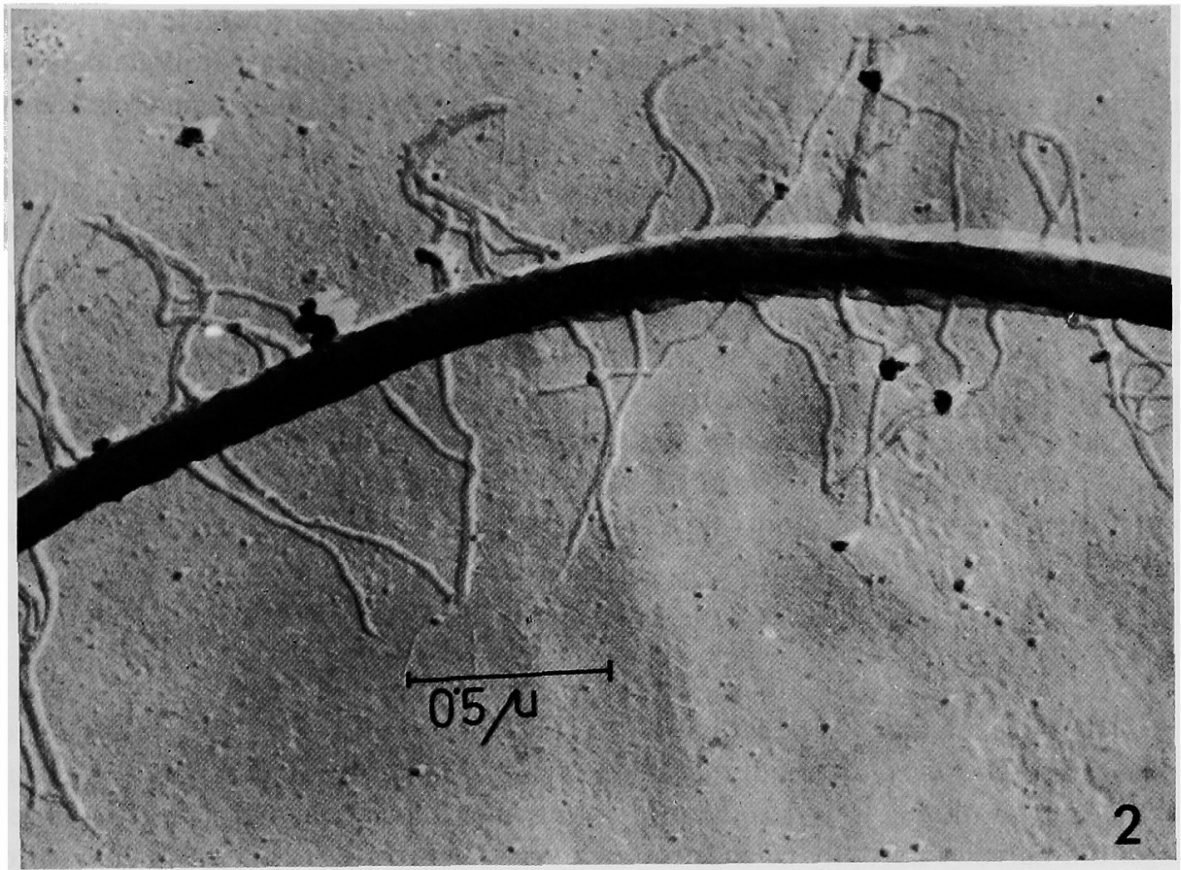

Fig. 2. Enlarged view of the lateral hairs on the tinsel flagellum. $\times 42000$.

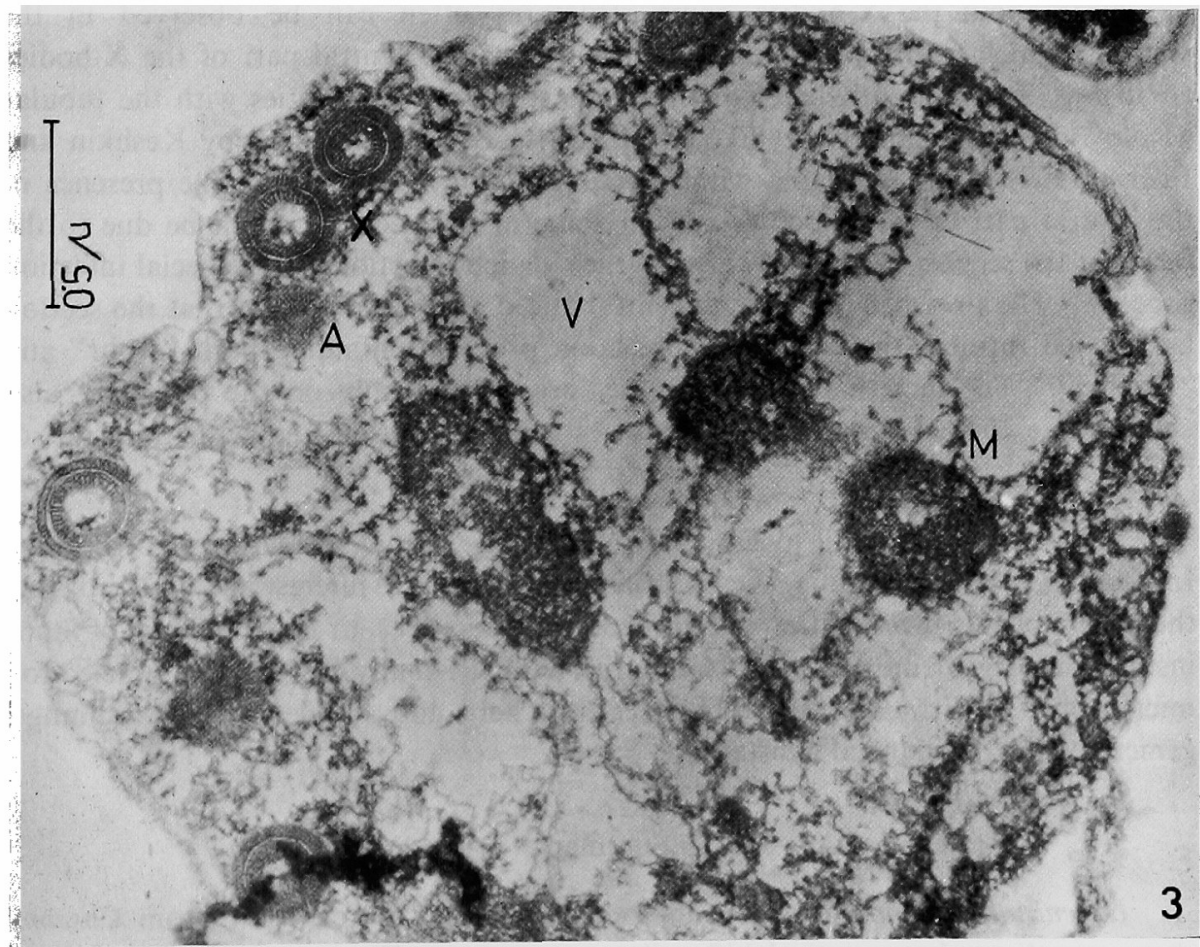

Fig. 3. Cross section of zoospore showing mitochondria (M), vacuole (V) and X-body. $\quad \times 44000$. 
Fig. 3), 0.45 to $0.52 \mathrm{~m} \mu$ in diameter, is bound by membranes which are folded inside. These are randomly distributed throughout the cytoplasm. Vacuoles (V in Fig. 3) are also randomly distributed in the cytoplasm. Some are apparently empty, but others contain electron dense particles.

There are a number of very interesting structures near the periphery of the zoospore body, described in the text as X-bodies ( $\mathrm{X}$ in Fig. 3). These structures consist of two parts. The outer part consists of a striated layer, 0.045 to $0.05 \mathrm{~m} \mu$ wide, bound by an external and inner membrane. The external membrane is double layered. The inner part of these structures, 0.15 to $0.16 \mathrm{~m} \mu$ in diameter, consists of highly aggregated threadlike structrues bound by a double layered membrane. The highly aggregated threadlike structures are sometimes absent in the central core of the inner part. In some of the cases in the area between the outer and inner parts, there are apparent empty spaces in the form of circular rings, but in some others, this is not clearly visible.

\section{Discussion}

The flagellar characters revealed here are truly typical of the biflagellate zoospores. However, the endpiece in the whiplash flagella is completely lacking in this preparation. It is also worth noting that the lateral hairs on the tinsel flagellum narrows abruptly at ends to form very fine tip (Fig. 2). In the literature so far examined, no similar other example has been found.

Near about the X-bodies, some structures often can be observed in the sections, which seem to be similar in structure as the central part of the X-bodies (A in Fig. 3). It seems that X-bodies have structural similarities with the tubular "Rohr" containing the bullet like "stachel" clearly demonstrated by Keshkin and Fuchs (1969) to be associated with infection of Polymyxa betae. The presence of the central part of the X-bodies only in some of our sections might be due to the fact that the section has passed through the "slauch" portion of the special infection process. The presence of both the central and outer parts indicate that the section has passed through the part of the infection process containing both "Rohr" and "Stachel". The fact that these X-bodies are present only on the periphery also substantiate the view that these structures might be associated with infection of host.

The author is grateful to Dr. Alwin Gaertner, Head, Department of Botany, Institut für Meeresforschung, West Germany for his active interest and advice during the course of this investigation and for providing facilities, to Frau Dr. Mix of Stattinstitut für Algemeine Botanik, Hamburg, West Germany for the use of electron microscope, to Frl. Manshart for technical help and to Deutsche Forschungsgemeinschaft for financial assistance.

\section{Summary}

Lagenisma coscinodisci, an endobiotic parasite of the centric diatom Coscinodiscus granii produces typical biflagellate zoospores. The special feature of the 
surface structures of these zoospores is that the lateral hairs on the tinsel flagellum narrows abruptly to form very fine tips. There are a number of interesting structures, described as X-bodies present near the periphery of the zoospore body. These bodies consist of distinct outer and inner parts and have structural similarities with 'Rohr' and 'Stachel' demonstrated by Keskin and Fuchs (1969) associated with the infection of Polymyxa betae.

\section{References}

Chakravarty, D. K. 1970. Production of pure culture of Lagenisma coscinodisci Drebes parasitising the marine diatom Coscinodiscus. Veroff. Inst. Meeresforsch. Bremerh. 11: 309-312.

Drebes, G. 1966. Ein parasitischer Phycomycet (Lagenidiales) in Coscinodiscus. Helg. Wiss. Meeresunters. 13: 426-435.

Gaertner, A. 1964. Electron mikroskopische Untersuchungen zum Sturktur der Geißein von Thraustrochytrium spec. Veroff. Inst. Meeresforsch. Bremerh. 9: 25-30.

Keskin, B. and Fuchs, W. H. 1961. Der Infektionsvorgang bei Polymyxa betae. Arch. Microbiol. 68: $218-226$. 